\title{
Letters
}

\section{Effectiveness and cost effectiveness of compression bandages should be shown}

Editor-Fletcher et al report their systematic review of compression treatment for venous leg ulcers. ${ }^{1}$ As researchers who perform randomised trials of compression bandages, we echo their concern that the quality of research is poor in this area.

A particular concern of ours is that, unlike pharmaceuticals, bandages (which are classified as medical devices), do not need to undergo rigorous clinical testing to establish effectiveness before being released on to the market. Moreover, provided that the product conforms to certain specifications, it may be placed on the drug tariff without trials in patients with the condition. While some manufacturers invest time and effort into performing properly controlled trials with adequate sample sizes to show statistical significance, many are dissuaded from doing so. Moreover, multilayer systems, which the paper indicates perform better than single layer bandages, are classified according to the individual bandages that make up the system rather than as a single unit.

Recently the NHS Executive called for proposals to examine methods that provide improved healing in patients with leg ulceration, and we await its decision on the allocation of funds. It is difficult to imagine, however, how appropriate trials can be performed on perhaps 10 different methods of compression, together with another five or so adjunctive treatments, without a coordinated national approach and suitable investment to achieve the quality required.

Using the results of the Stockport and Trafford study, ${ }^{2}$ we estimate that at least $£ 20 \mathrm{~m}$ is spent annually on disposables for leg ulcer treatment in Britain, of which about half is spent on bandages. Clearly, evaluation is needed of the effectiveness of these treatments, which seem to offer maintenance treatment rather than healing.

We believe that, until manufacturers have to prove evidence of the effectiveness and cost effectiveness of their products in a similar way to that required of the pharmaceutical industry, they will be content to continue producing "me too" bandages, for which they know there is a market, rather than introducing innovations in bandage technology. The principal treatment for venous ulceration is high compression treatment. Now seems to be the time to evaluate the methods of delivering this treatment, with the aim of avoiding undue waste and unnecessary suffering by the use of ineffective treatments.

Peter J Franks Codirector

Christine J Moffatt Codirector

Centre for Research and Implementation of Clinical Practice at Thames Valley University, Wolfson Institute of Health Sciences, London W5 2BS

1 Fletcher A, Cullum N, Sheldon TA. A systematic review of compression treatment for venous leg ulcers. $B M$ 1997;315:576-80. (6 September.)

2 Simon DA, Freak L, Kinsella A, Walsh J, Lane C, Groarke L, et al. Community leg ulcer clinics: a comparative study in two health authorities. BMJ 1996;312:1648-51.

\section{Claim for major advance in treatment of perforated peptic ulcer seems premature}

EDITOR-In their review of recent advances in general surgery Corvera and Kirkwood conclude that recognition of the importance of Helicobacter pylori in perforated peptic ulcer disease has led to a change in management strategy. ${ }^{1}$ They advocate a move away from acid-reductive surgery to simple closure with subsequent anti- $H$ pylori treatment. While a reduction in the complexity of surgical intervention might be welcome, the published evidence does not support such a central role for medical anti- $H$ pylori treatment in perforated peptic ulcer disease.

Successful eradication of $H$ pylor $i$ alters the natural course of chronic uncomplicated peptic ulcer disease, ${ }^{2}$ and recent controlled and uncontrolled studies have shown that clearance of the bacteria reduces the rate of rebleeding after an episode of peptic ulcer haemorrhage. ${ }^{3}$ The situation for perforated ulcers, however, is much less clear cut. Perforated ulcers may represent a specific subgroup of peptic ulcer disease, and anti- $H$ pylori treatment may have a much less important role (if any). Reinbach et al found that perforated duodenal ulcer was not associated with $H$ pylori infection: $47 \%$ of patients with perforated ulcer were seropositive for the bacteria, compared with $50 \%$ of matched hospital controls ${ }^{4}$; this is clearly lower than the $90-100 \%$ positivity in chronic uncomplicated duodenal ulceration. Additionally, the small study that Corvera and Kirkwood cite regarding omental patch repair was uncontrolled and contained no data on eradication of $H$ pylori or long term follow up. ${ }^{5}$ Thus the authors' suggested management strategy has not been subjected to formal trial, and the epidemiological association between $H$ pylori infection and perforated ulcer remains in doubt.

Clinicians are unlikely to withhold anti- $H$ pylori treatment in infected patients with perforated peptic ulcers. Follow up is advised after attempted eradication of $H$ pylori from bleeding ulcers to ensure that the eradication has been effective, and it also seems necessary after perforation. ${ }^{3}$ This leaves the problem of what to do about those ulcers that were never infected. While the policy advocated by Corvera and Kirkwood may be both sensible and effective and may well be supported by future studies, it seems premature to base a claim regarding a major advance in the treatment of perforated peptic ulcer on such slim and contradictory evidence.

Ian L P Beales Lecturer in internal medicine and gastroenterology

Department of Gastroenterology, West Norwich Hospital, Norwich NR2 3TU

1 Corvera CU, Kirkwood SK. Recent advances: general surgery. BMJ 1997;315:586-9. (6 September.)

2 Tytgat GN. No Helicobacter pylori, no Helicobacter pyloriassociated peptic ulcer disease. Aliment Pharmacol Ther 1995;9(suppl 1):39-42.

\section{Advice to authors}

We receive more letters than we can publish: we can currently accept only about one third. We prefer short letters that relate to articles published within the past four weeks. We also publish some "out of the blue"letters, which usually relate to matters of public policy.

When deciding which letters to publish we favour originality, assertions supported by data or by citation, and a clear prose style. Letters should have fewer than 400 words (please give a word count) and no more than five references (including one to the BMJ article to which they relate); references should be in the Vancouver style. We welcome pictures.

Letters, whether typed or sent by email, should give each author's current appointment and full address. Letters sent by email should give a telephone and fax number when possible. We encourage you to declare any conflict of interest. Please send a stamped addressed envelope if you would like to know whether your letter has been accepted or rejected.

We may post some letters submitted to us on the world wide web before we decide on publication in the paper version. We will assume that correspondents consent to this unless they specifically say no.

Letters will be edited and may be shortened. 
3 Laine LA. Helicobacter pylori and complicated ulcer disease. Am J Med 1996;100:52-7S

4 Reinbach DH, Cruickshank G, McColl KE. Acute perforated duodenal ulcer is not associated with Helicobacter pylori infection. Gut 1993;34:1344-7.

5 Sebastian M, Chandran VP, Elashaal YI, Sim AJ Helicobacter pylori infection in perforated peptic ulcer disease. Br J Surg 1995;82:360-2.

\section{Debate over screening for gestational diabetes}

\section{Screening should take place only in context of good quality controlled trials}

EDITOR-Jarrett and Soares et al present arguments respectively against and in favour of screening for gestational diabetes. ${ }^{1}$ Jarrett has been arguing objectively against gestational diabetes as a useful concept for many years. ${ }^{2}$ In contrast, many obstetricians and diabetologists have aggressively sought and treated this condition despite a lack of real evidence. Rather, they have worked on the assumption that there is a continuum from normal glucose tolerance through gestational diabetes to frank diabetes and that gestational diabetes must be a less severe form of diabetes.

Screening for gestational diabetes presents a massive organisational and financial cost as well as a stressful burden to the women concerned. As Walkinshaw has shown, there is no evidence that attempts to control carbohydrate metabolism in women labelled as having gestational diabetes usefully alter perinatal outcome; rather, they lead to unnecessary interference. ${ }^{3}$ Had either Jarrett or Soares et al referred to Walkinshaw's systematic review then one of the three arguments of Soares et al for screening could have immediately been dismissed as lacking in supportive evidence. Their other two arguments are no more certain: that the presence of gestational diabetes predicts an increased risk of maturity onset diabetes in later life, and that management of carbohydrate metabolism in the mother may prevent the child from developing long term medical problems as a result of an adverse intrauterine environment.

Sufficient evidence probably exists to support the case that a degree of glucose intolerance predicts an increased risk of frank diabetes in later life. What is less clear is whether, as a result of subjects at increased risk being identified, any intervention can alter disease progression. Surely if there were such evidence, confining screening for such glucose intolerance solely to women who happen to be pregnant would be massively unfair-what about men with an increased risk of maturity onset diabetes, and childless women?

The hypothesis regarding long term metabolic effects of an adverse (carbohydrate) intrauterine environment requires confirmation by prospective studies. In discussing this hypothesis Soares et al ignore the difference between frank diabetes and gestational diabetes once more.

Until the relevance of gestational diabetes is known, screening for it should take place only in the context of good quality controlled trials. In the meantime we should continue to ensure good preconceptional and antenatal control of frank diabetes and aim to detect the few women who have frank diabetes not diagnosed before pregnancy. The benefits of treating such women have been shown by many authors.

Malcolm Griffiths Obstetrician and gynaecologist Luton and Dunstable Hospital, Luton LU4 0DZ Malcolm@mgriff22.demon.co.uk

1 Jarrett RJ, Soares JdeAC, Dornhorstt A, Beard RW. Should we screen for gestational diabetes? BMJ 1997:315:736-9. (20 September:)

2 Jarret RJ. Gestational diabetes: a non-entity? $B M J$ 1993;306:37-8

Walkinshaw SA Dietary regulation for "osestation diabetes" In: Neilson JP, Crowther CA Hodnett ED, Habetes." In: Neils JP, Crom Pr. CA, Hodnett ED, Hofmeyr GJ, Keirse MJNC, eds. Pregnancy and childbirt module, Cochrane database of systematic reviews. Oxford: Updat. Sof ware, 1997. Updated quant ly, updated 3 June and CD ROM). Cochrane Collaboration, issue 3.)

\section{Scientific uncertainty is mirrored in} clinical practice in Italy

Editon-The debate on screening for gestational diabetes underlines how the question about the potential benefits of such screening remains controversial. ${ }^{1}$ Jarrett writes, "No clear benefit has been shown from screening for glucose intolerancehyperglycaemia ... during pregnancy." On the other hand, Soares et al believe that such screening could improve perinatal outcome and give mothers the possibility to reduce their own and their babies' risk of later diabetes.

Scientific controversies are often reflected in clinical practice. To evaluate the attitudes of Italian gynaecologists towards the monitoring of normal pregnancy, we sent a postal questionnaire to 504 physicians in charge in 57 obstetric and gynaecology centres affiliated to the Association of Italian Gynaecologists and Obstetricians. Although these 57 centres do not formally represent the Italian obstetric departments, the centres that replied were no different from the average Italian obstetric departments as regards geographical distribution.

A total of 283 gynaecologists returned the completed questionnaire. Among several questions was one asking: "During a normal pregnancy do you routinely carry out the O'Sullivan test?" This screening test for gestational diabetes is described by Soares et al. Altogether 151 gynaecologists said that they did carry out the test for all pregnant women $(55$ gave a $50 \mathrm{~g}$ oral glucose load and 26 a 100 g glucose load) 60 said that they carried out the test only for women with risk factors, such as obesity and a family history. The remaining 72 gynaecologists did not believe the test to be necessary during a normal pregnancy.

In conclusion, uncertainty in the scientific field is mirrored in clinical practice: half of the gynaecologists who answered our questionnaire believed that there were benefits in screening for gestational diabetes, and half did not. As Jarrett says, "Much confusion surrounds the topic of screening for glucose intolerance- hyperglycaemia in pregnancy." International and national scientific societies should produce guidelines for screening for gestational diabetes in order to minimise the discrepancies in practice among gynaecologists.

Francesca Chiaffarino Research fellow

Fabio Parazzini Head, analytical epidemiology unit Angela Bortolotti Researcher

Istituto di Ricerche Farmacologiche "Mario Negri", via Eritrea 62, 20157 Milan, Italy

Guido Benzi Researcher

Prima Clinica Ostetrico Ginecologica, Universita degli Studi di Milano, 20100 Milan

1 Jarrett RJ, Soares JdeAC, Dornhorstt A, Beard RW. Should we screen for gestational diabetes? BMJ 1997;315:736-9. (20 September.)

\section{Evidence from randomised controlled} trial is needed

EDITOR-Soares et al argue in favour of screening for gestational diabetes, using some of the poorest levels of evidence possible-case-control and cross sectional data, as well as early observational studies hypothesising that intrauterine exposure to hyperglycaemia may lead to type 2 diabetes in the child. ${ }^{1}$ What is lacking is a large randomised single-masked controlled clinical trial to resolve many unanswered questions. Foremost of these questions is whether screening all women, as is the practice in most centres, leads to lower rates of caesarean delivery, use of forceps, and shoulder dystocia. Secondly, can prospectively defined subgroups be identified from such a trial, on the basis of a family history of type 2 diabetes, ethnicity, or body mass index, to better predict who might truly have insulin resistance during pregnancy and develop it again later in life?

Without such a trial, we have wasted our time quoting studies that have little to do with validating the effectiveness of a screening programme that costs a lot of time and money without evidence of benefit. Until such a trial is carried out, universal screening for gestational diabetes should be postponed.

Joel Ray Clinical fellow

Obstetrical medicine programme, University of Toronto, 363 Soraruren Ave, Toronto, ON, Canada M6R 2G5

1 Jarrett RJ, Soares JdeAC, Dornhorstt A, Beard RW. Should we screen for gestational diabetes? BMJ 1997;315:736-9. (20 September.)

\section{Health status instruments should satisfy full range of methodological criteria}

EDITOR-Dorman et al are right to draw attention to the higher response rate achieved with the EuroQol questionnaire compared with the SF-36 instrument among survivors of stroke. ${ }^{1}$ Published work on health related quality of life overlooks the burden that instruments impose on patients, studies often failing to report response and completion rates. Dorman et al did not mention, however, that the approach selected to measure health related quality of 
life should be methodologically sound and satisfy criteria for accuracy, reliability, validity, responsiveness, generalisability, and sensibility.

Although evidence exists for the testretest reliability and construct validity of the EuroQol questionnaire, ${ }^{23}$ direct comparisons with other health status instruments suggest that further research is required to improve its methodological robustness and performance in different clinical contexts. Brazier et al tested the completion, reliability, and validity of the SF-36 and the EuroQol questionnaire in an elderly female population. ${ }^{4}$ Although the SF-36 had poorer rates of completion than the EuroQol questionnaire, it showed greater sensitivity to lower degrees of illness. Further work is also needed to evaluate more fully the sensitivity of the EuroQol questionnaire to change over time. The evidence published by Hollingworth et al suggests that the EuroQol questionnaire may be less responsive than the SF-36 in assessing change in health status. ${ }^{5}$

The selection of instruments to measure the health related quality of life of patients should be determined by the research questions being asked and the specific characteristics of the patients being studied. All instruments considered for selection should satisfy a comprehensive range of methodological criteria and should not be promoted on the basis of simplicity or response frequencies.

Stavros Petrou Health economist

National Perinatal Epidemiology Unit, University of Oxford, Radcliffe Infirmary, Oxford OX2 6HE

1 Dorman PJ, Slattery J, Farrell B, Dennis MS, Sandercock PAG, United Kingdom Collaborators in the Internationa Stroke Trial. A randomised comparison of the Euro and Short Form-36 after stroke. BMJ 1997;315:461. (23 and Short

2 Van Agt HM, Essink Bot ML, Krabbe PF, Bonsel GJ. Test-retest reliability of health state valuations collected Test-retest reliability of health state valuations collected
with the EuroQol questionnaire. Soc Sci Med with the Euro

3 Hurst NP, Jobanputra P, Hunter M, Lambert M, Lochhead A, Brown H. Validity of EuroQol-a generic health status instrument-in patients with rheumatoid arthritis. Economic and Health Outcomes Research Group. $\mathrm{Br} J$ Rheumatol 1994;33:655-62.

4 Brazier JE, Walters SJ, Nicholl JP, Kohler B. Using the SF-36 and EuroQol on an elderly population. Qual Life Res 1996;5:195-204.

5 Hollingworth W, Mackenzie R, Todd CJ, Dixon AK. Measuring changes in quality of life following magnetic resonance imaging of the knee: SF-36, EuroOol or Rosser Index? Qual Life Res 1995;4:325-34.

\section{Effect on mortality of switching from cigarettes to pipes or cigars}

\section{Study underestimated difference in risk}

EDITOR-In their study of lung cancer and other diseases in male pipe and cigar smokers, Wald and Watt seem to have underestimated the difference in the risk of lung cancer between male current smokers and lifelong non-smokers (a 16-fold difference in their study). ${ }^{1}$ Non-smokers accounted for seven of 102 lung cancers in the study (figures for most ex-smokers were not supplied). This is very different from the experience of Capewell et al, who studied 3070 Scottish patients with lung cancer. ${ }^{2}$ Only $0.7 \%$ of men with lung cancer were lifelong non-smokers. My experience in Salford (three $(0.8 \%)$ non-smokers and 217 current smokers among 380 men with lung cancer) is almost identical with that of Capewell et al. On the basis of local data on the prevalence of smoking, I calculate a 62-fold increased risk of lung cancer for Salford smokers compared with non-smokers. Capewell et al's figures would also imply a risk of cancer of at least 50-fold for current smokers.

There are several possible explanations for the high proportion of non-smokers with lung cancer in Wald and Watt's study. Firstly, this was an elite group of subjects (business and professional men), of whom only a fifth smoked; one would therefore expect proportionally more cancers among non-smokers. In a previous study of professional British male subjects (the British doctors study), however, only seven $(1.6 \%)$ of 441 deaths from lung cancer occurred in non-smokers. ${ }^{3}$ Secondly, the number of lung cancers in Wald and Watt's study was small (102 cases), so the finding of seven cancers in non-smokers (compared with an expected finding of one or two cancers based on the above studies) may have occurred by chance. Thirdly, some long term ex-smokers in Wald and Watt's study may have described themselves as non-smokers (Capewell et al found that at least a quarter of "non-smokers" were really ex-smokers).

Whatever the explanation, Wald and Watt seem likely to have overestimated the risk of lung cancer in lifelong non-smokers compared with that in larger British studies. It is therefore important to emphasise to smokers in the general population that their risk of lung cancer is far more than 16 times that of a non-smoker and that this risk can be reduced greatly by stopping smoking. It is also likely that pipe and cigar smokers (and long term ex-cigarette smokers) are at greater relative risk of lung cancer compared with non-smokers than suggested in the authors' study.

B Ronan O'Driscoll Consultant respiratory

physician

Hope Hospital, Salford M6 8HD

1 Wald NJ, Watt HC. Prospective study of effect of switching from cigarettes to pipes or cigars on mortality from thre smoking related diseases. BMJ 1997;314:1860-3. (28 June.) 2 Capewell S, Sankaran R, Lamb D, McIntyre M, Sudlow MI. Lung cancer in lifelong non-smokers. Thorax 1991;46:565-8

3 Doll R, Peto R. Mortality in relation to smoking: 20 years observations on male British doctors. BMJ 1976;ii: 1525-36.

\section{Patterns of inhalation are important}

EDITOR-Wald and Watt reported that switching from smoking cigarettes to pipes or cigars would roughly halve cigarette smokers' risk of dying of smoking related disease. ${ }^{1}$ If this were true it would be of great importance for public health. But it does not follow from the data presented.

Men who had switched to pipes or cigars at least 20 years before entering the study (switchers) were observed to have a lower risk of dying than those who continued smoking cigarettes. Cigarette smokers generally reported deeper inhalation and had higher blood carboxyhaemoglobin concentrations than either primary pipe or cigar smokers or switchers. The best predictor of risk was the measure of inhaled smoke (carboxyhaemoglobin concentration) taken at entry, and after allowance was made for this, the smoking category had no significant predictive value. The conclusion that switching conferred a benefit therefore hinges on the assumption that it caused a lowering of smoke intake. But no information is presented on switchers' intakes when they were cigarette smokers. They may or may not have had intakes similar to those of the men who continued to smoke cigarettes. If, as is entirely possible, they were already lighter smokers than the continuing cigarette smokers, their observed lower risk may be attributable to patterns of inhalation established before they switched from cigarettes and largely maintained after switching.

It would be unfortunate if cigarette smokers were encouraged by this report to switch to pipes or cigars. Data from the large multiple risk factor intervention trial indicate little reduction in exposure after switching. ${ }^{23}$ Nicotine addicts are notorious for grasping at any straw rather than give up completely. Modern small cigars are particularly unlikely to confer any benefit, as they are designed, packaged, and promoted to be as like cigarettes as possible.

Martin J Jarvis Reader in health psychology ICRF Health Behaviour Unit, Department of Epidemiology and Public Health, University College London, London WC1E 6BT

\section{Wald NJ, Watt HC. Prospective study of effect of switching from cigarettes to pipes or cigars on mortality from three smoking related diseases. BM/ 1997;314:1860-3. (28 June.) 2 Ockene JK, Pechacek TF, Vogt T, Svendsen K. Does switch- ing from cigarettes to pipes or cigars reduce tobacco smoke exposure? Am J Public Health 1987;77:1412-6. \\ 3 Jarvis MJ, West R, Tunstall-Pedoe H, Vesey C. An evaluation of the intervention against smoking in the multiple risk factor intervention trial Pres Med $1984 ; 13: 501-9$}

\section{"Switchers" will have had higher cumulative exposure to tobacco}

EDITOR-Wald and Watt reported increased mortality related to smoking among cigar and pipe smokers who previously smoked cigarettes (switchers) compared with cigar and pipe smokers who had not previously smoked cigarettes (non-switchers). ${ }^{1}$ We have some concerns about the validity and interpretation of the findings, and would like to add to the authors' key messages.

The validity of their findings is weakened by incomplete data on exposure. There were no data on duration of smoking before entry to the study, and exposure status was categorised on the basis of a single assessment of current smoking behaviour at the time of entry, with no reassessment during follow up. This could introduce bias if, for example, switchers were subsequently more or less likely to give up smoking entirely than nonswitchers. There is also a paucity of data on possible confounding factors other than 
blood pressure and blood cholesterol concentrations at entry.

Even if the principal finding is accepted as valid, we question the explanation offered for it. We believe that a higher cumulative exposure to tobacco (a known predictor of mortality, particularly from lung cancer ${ }^{2}$ ) among switchers is more likely to account for the observed differences in mortality than are minor variations in inhaling. This is for two reasons. Firstly, switchers are by definition former cigarette smokers, who, as the paper shows, have a higher consumption of tobacco than cigar and pipe smokers. Secondly, switchers are likely to have had a longer duration of exposure to tobacco since they had all given up smoking cigarettes at least 20 years before the health examination, and there were no reported criteria for duration of smoking among non-switchers.

The study confirms previous findings that mortality is higher among cigar and pipe smokers than non-smokers. ${ }^{3}$ Therefore, we believe that healthcare workers should advise cigar and pipe smokers to give up completely and, if the findings from this study are confirmed, could justifiably concentrate their efforts on cigar and pipe smokers who formerly smoked cigarettes as a particularly high risk group.

Richard Edwards Lecturer in epidemiology and public health

Department of Epidemiology and Public Health, Medical School, University of Newcastle, Newcastle upon Tyne NE2 4HH

Michael Jakubovic Specialist registrar in public health medicine

County Durham Health Authority, County Durham DL1 5XZ

Wald NJ, Watt HC. Prospective study of effect of switching from cigarettes to pipes or cigars on mortality from three smoking related diseases. BMJ 1997;314:1860-3. (28 June.)

2 Kahn HA. The Dorn study of smoking mortality among US vet erans. Bethesda, MD: National Cancer Institute, 1966 1-125. (National Cancer Institute monograph 19.)

3 Doll R, Peto R. Mortality in relation to smoking: 20 years observations on male British doctors. BMJ 1976;i: 1525-36.

\section{American study supported conclusions}

EDITOR-Wald and Watt presented results of a prospective study indicating that cigarette smokers decrease their chance of death from ischaemic heart disease, lung cancer, and chronic obstructive lung disease by switching to cigars or pipes. ${ }^{1}$ The study was limited by small numbers of deaths, particularly from lung cancer, on which changing smoking habits would be expected to have the greatest impact; an inability to evaluate cigar and pipe smoking separately; and the use of disease mortality rather than incidence. The findings prompted us to re-examine data from a large case-control study of lung cancer carried out at seven locations in Europe.

There were 6919 male incident cases of lung cancer and 13458 controls, ${ }^{23}$ including 573 cases and 1036 controls who smoked cigarettes and cigars or pipes and 15 cases and 56 controls who switched from cigarettes to cigars or pipes. Previous analyses concluded that cigarette smokers who switched from non-filter to filter cigarettes or
Table 1 Number of cases and controls in study by status as current or former smoker, ${ }^{*}$ and relative risk of lung cancert; data are on men only

\begin{tabular}{|c|c|c|c|c|c|c|}
\hline \multirow[b]{2}{*}{ Smoking status } & \multicolumn{2}{|c|}{ Current smoker } & \multicolumn{2}{|c|}{ Former smoker } & \multicolumn{2}{|c|}{ Relative risk $(95 \% \mathrm{Cl})$} \\
\hline & Cases & Controls & Cases & Controls & Current smoker & Former smoker \\
\hline Cigarettes only & 5131 & 6681 & 911 & 2662 & 11.2 (9.6 to 13.1$)$ & 4.52 (3.8 to 5.3$) \ddagger$ \\
\hline Cigars only & 28 & 98 & 9 & 46 & 3.69 (2.4 to 5.8$)$ & 2.40 (1.2 to 5.0$)$ \\
\hline Pipe only & 35 & 165 & 4 & 32 & 2.91 (2.0 to 4.3$)$ & 1.54 (0.6 to 4.5$)$ \\
\hline Cigarettes and cigars§ & 138 & 230 & 32 & 97 & 7.92 (6.1 to 9.6$)$ & $4.12(2.7$ to 6.3$) \neq$ \\
\hline $\begin{array}{l}\text { Switch from cigarettes to } \\
\text { cigars } \|\end{array}$ & 8 & 29 & 1 & 5 & 3.95 (1.8 to 8.8$)$ & $2.42(0.3$ to 20.9$)$ \\
\hline Cigarettes and pipes§ & 262 & 367 & 42 & 164 & 9.88 (7.9 to 12.3$)$ & $3.37(2.3$ to 4.9$) \ddagger$ \\
\hline $\begin{array}{l}\text { Switch from cigarettes to } \\
\text { pipes***}\end{array}$ & 5 & 15 & 1 & 7 & 4.57 (1.6 to 12.8$)$ & $2.00(0.2$ to 16.4$)$ \\
\hline Cigars and pipes & 17 & 48 & 6 & 17 & 4.46 (2.5 to 7.9$)$ & $3.93(1.5$ to 10.1$)$ \\
\hline Cigarettes, cigars, and pipes & 76 & 111 & 23 & 67 & $9.12(6.6$ to 12.7$)$ & $4.42(2.7$ to 7.3$) \ddagger$ \\
\hline
\end{tabular}

${ }^{*}$ Current smokers included those who stopped smoking within five years of date of occurrence of cancer (cases) or interview (controls).

†Reference category was lifelong non-smokers (190 cases and 2617 controls). Relative risks were adjusted for age and study location.

†Relative risks significantly different for current and former smokers, $P<0.01$

$\S$ Subjects who consumed cigarettes and cigars or pipes concurrently.

IMean of 18 years (median 15 years) from cessation of cigarette use to age at diagnosis (case) or interview (control).

${ }^{* \star}$ Mean of 24 years (median 21 years) from cessation of cigarette use to age at diagnosis (case) or interview (control).

Table 2 Number of cases and controls for cigarette and cigar smokers or cigarette and pipe smokers by status as current or former smoker* and relative risk of lung cancer†

\begin{tabular}{|c|c|c|c|c|c|c|}
\hline & \multicolumn{2}{|c|}{$\begin{array}{l}\text { Current cigarette } \\
\text { smoker }\end{array}$} & \multicolumn{2}{|c|}{$\begin{array}{l}\text { Former cigarette } \\
\text { smoker }\end{array}$} & \multicolumn{2}{|c|}{ Relative risk $(95 \% \mathrm{Cl})$} \\
\hline & Cases & Controls & Cases & Controls & $\begin{array}{l}\text { Current cigarette } \\
\text { smoker }\end{array}$ & $\begin{array}{l}\text { Former cigarette } \\
\text { smoker }\end{array}$ \\
\hline Current cigar smoker & 93 & 138 & 21 & 58 & 10.9 (7.8 to 15.4$)$ & 5.01 (2.9 to 8.7$)$ \\
\hline Former cigar smoker & 24 & 34 & 32 & 97 & 12.4 (7.0 to 22.0$)$ & 4.59 (2.9 to 7.2$)$ \\
\hline Current pipe smoker & 145 & 195 & 28 & 52 & 11.6 (8.7 to 15.4$)$ & 7.63 (4.6 to 12.6$)$ \\
\hline Former pipe smoker & 88 & 120 & 42 & 164 & $11.4(8.2$ to 15.9$)$ & 3.52 (2.4 to 5.2 ) \\
\hline
\end{tabular}

${ }^{*}$ Current smokers included subjects who stopped smoking within five years of date of diagnosis (cases) or interview (controls). Table excludes smokers who switched from cigarettes to cigars or pipes; cigar and pipe smokers; and cigarettes, cigars, and pipe smokers.

†Reference category was lifelong non-smokers (190 cases and 2617 controls). Relative risks were adjusted for age and study location.

reduced the number of cigarettes smoked per day lowered their risk of lung cancer. ${ }^{4}$

Relative risks of lung cancer were lower for former than current smokers (table 1). In addition, relative risks for cigarette and cigar or pipe smokers were lower than those for cigarette-only smokers but higher than those for cigar-only, pipe-only, and cigar and pipe smokers. Those who switched from cigarettes to cigars or pipes had risks similar to those of cigar-only and pipe-only smokers.

For cigarette and cigar or pipe smokers, relative risks for former smokers declined only if subjects stopped smoking cigarettes (table 2). The relative risk was 10.9 for current cigarette and cigar smokers, increased to 12.4 for former cigar smokers who continued to smoke cigarettes, and fell to 5.0 for former cigarette smokers who continued to smoke cigars. The relative risk for subjects who stopped smoking cigarettes and cigars was 4.6. A similar pattern occurred for cigarette and pipe smokers. Relative risks were 11.6 for current cigarette and pipe smokers, 11.4 for former pipe smokers who continued smoking cigarettes, 7.6 for former cigarette smokers who continued smoking pipes, and 3.5 for subjects who stopped smoking cigarettes and pipes.

Our analysis showed that cigarette smokers who switch to cigars or pipes reduce their risk of lung cancer, thus supporting the conclusion of Wald and Watt. We also found that mixed smokers who stop smoking cigarettes but continue smoking cigars or pipes also lower their risk of lung cancer, although they continue to incur a risk five times higher than that of nonsmokers.

Jay H Lubin Mathematical statistician

Joseph F Fraumeni Jr Director

Division of Cancer Epidemiology and Genetics, National Cancer Institute, National Institutes of

1 Wald NJ, Watt HC. Prospective study of effect of switching from cigarettes to pipes or cigars on mortality from three smoking related diseases. BMJ 1997;314:1860-3. (28 June.) $\mathrm{M}$, et al. Patterns of lung cancer risk among filter and nonfilter smokers. Int J Cancer 1984;33:569-76.

3 Lubin JH, Richter BS, Blot WJ. Lung cancer risk with cigar and pipe use. JNCI 1984;73:377-82.

4 Lubin JH, Blot WJ, Berrino F, Flamant R, Gillis CR, Kunze $\mathrm{M}$, et al. Modifying risk of developing lung cancer by changing habits of cigarette smoking BMJ 1981; 288:1953-6.

5 Lubin JH Modifying risk of developing lung cancer by changing habits of cigarette smoking. BMJ 1984;289:921.
chang

\section{Authors' reply}

EDITOR-The risk of lung cancer among current cigarette smokers compared with lifelong non-smokers in our paper (a 16 -fold increase) is virtually the same as that found in the prospective study of British Health, Bethesda, MD 20892, USA

2 Lubin JH, Blot WJ, Berrino F, Flamant R, Gillis CR, Kunze 
physicians (a 15-fold increase). ${ }^{1}$ This confirms that our estimate of risk is reasonably accurate. The risk of death from lung cancer in lifelong non-smokers was 7.8 per 100000 per year $(95 \%$ confidence interval 3.7 to $16.5)$ in our study, which was of men aged 35-64 at entry who were followed up for an average of 14 years and 4 months.

Jarvis expresses concern that the men who switched from smoking cigarettes to smoking pipes and cigars (switchers) may have had lower former cigarette consumption than those who continued to smoke cigarettes, in which case there would not necessarily be a reduction in risk because it would be lower anyway. This is possible, although our data suggest that, if so, it had only a small effect. In men aged 15-24 the mean cigarette consumption in switchers and continuing cigarette smokers was the same, and in men aged 25-34 it was on average three cigarettes a day lower among switchers. This indicates that most of the difference in risk between switchers and continuing cigarette smokers is likely to be a reduction in risk as a result of switching.

We agree with Edwards and Jakubovic that obtaining repeated measures of smoking habit would improve the precision of smoking data, but it is remarkable that a single assessment of smoking was so predictive of mortality many years later. If there were any error, it is more likely that it would have masked effects, not "created" them. We believe that confounding is a material issue only with respect to heart disease, and we adjusted for blood pressure and serum cholesterol concentration, which are two factors that are strongly related to ischaemic heart disease. It is unlikely that other factors would introduce significant confounding. We acknowledge that the amount of tobacco smoked per day may be more important than the extent of inhaling in determining risk of smoking related death, but there is evidence that both are involved.

Finally, we were pleased to see the corroborative results of Lubin and Fraumeni.

N J Wald Professor

H C Watt Statistician

Department of Environmental and Preventive Medicine, Wolfson Institute of Preventive Medicine, St Bartholomew's and the Royal London School of Medicine and Dentistry, London EC1M 6BQ

1 Doll R, Peto R, Wheatley K, Gray R, Sutherland I. Mortality in relation to smoking: 40 years' observations on male British doctors. BMJ 1994;309:901-11.

\section{Fact that no SHO post was given five years' approval is worrying}

EDITOR-In his letter about the approval of senior house office posts, Lloyd (the secretary of the Royal College of Physicians) explains that limited approval is given to posts that are found to be inadequate. ${ }^{1}$ In attempting to defend the college he highlights a fundamental facet of the problem. He states that "each quarter the director of training submits to the coun- cil a report on posts visited. If everything is in order a post is given approval for five years." He then points out that none of the last 388 posts inspected was found acceptable enough to be given approval for five years. This suggests either that the overall standard of training is so poor that no hospital makes the grade or that the college is being unrealistic in its options. Neither of these, I would have thought, is something to be proud of.

Lloyd states that withdrawal of approval for training has serious repercussions for the provision of services. Thus, obviously, any trust that wishes to avoid having a senior house officer post withdrawn should merely ensure that its juniors are so overworked that the college could not possibly think of removing approval.

I would like to think that the director of training is more worried about the possible impact on the individual trainee. What should be available is a system for picking up those trainees who have been ill served and perhaps finding them a remedial placement.

Keith Dave Consultant ophthalmologist Huddersfield Royal Infirmary, Huddersfield HD3 3EA

\section{Lloyd DB. Approval of SHO posts is rarely withdrawn bu is often given for limited time. BMJ 1997;315:1163. (1 November.)}

\section{BUPA and the tobacco industry}

\section{Chairperson of BUPA in Republic of} Ireland is also chairperson of tobacco producer

EDITOR-I was delighted to see that Wald and Watt, from the BUPA Epidemiological Research Group, were able to state conclusively that there were no conflicts of interest evident in their study on smoking related diseases. ${ }^{1}$ In the same issue of the $B M J$ the BUPA Foundation advertised generous research awards for communication, epidemiology, health at work, and research. Could this be the same BUPA that has recently established a division in the Republic of Ireland and has had the foresight to appoint one of our most successful businesswomen, Dr Margaret Downes, as its chairperson? That she is also the chairperson of one of the biggest tobacco producers in the Republic of Ireland (Gallaher) seems to be irrelevant to BUPA. One cannot readily criticise Dr Downes for accepting the offer to chair BUPA Ireland-after all, being chairperson of BUPA must offer some degree of respectability, and the tobacco industry is in short supply of that. Furthermore, it is probably the best each-way bet one could hope for (especially if you work for the tobacco industry)-profits when the smokers are smoking and profits when the smokers are dying.

Surely someone in BUPA can see the potential conflicts of interest in this appointment. If they have difficulty in doing so, perhaps some of the recipients of their largesse in the United Kingdom would point out the hard realities to them and do us all a favour.

Fenton Howell* Specialist in public health medicine European Medical Association Smoking or Health, Laytown, Meath, Republic of Ireland

*Fenton Howell is a member of the European Medical Association Smoking or Health and a member of the board of ASH Ireland.

1 Wald NJ, Watt HC. Prospective study of effect of switching smoking related diseases. BMJ 1997;314:1860-3. (28 June.)

\section{Reply from BUPA Ireland}

Editor-Dr Margaret Downes is a highly respected non-executive chairman of BUPA Ireland, whose skills and integrity are widely recognised. As with her many other directorships, she is not involved in the day to day operations or decision making of this company. Her primary responsibilities relate to board and corporate governance matters, for which she is eminently qualified.

It is public policy in Ireland, under the 1994 Health Insurance Act, to operate a community rated system which does not discriminate between subscribers to health insurance because of their lifestyle choices. BUPA Ireland is bound by the public policy requirements.

The fact that Dr Downes is the chair of Gallaher Ireland and of BUPA Ireland is public information, and no attempt has been made to conceal it. She was appointed by BUPA because of her expertise in financial services, health care, and business management: she was the best person for the job.

Martin O'Rourke Managing director BUPA Ireland, 12 Fitzwilliam Square, Dublin 2 , Republic of Ireland

\section{Community based programmes can help to manage tuberculosis more effectively}

EDITOR-In many low income countries the cure rates achieved by tuberculosis field programmes (for sputum smear positive cases) exceed the $85 \%$ target set by the World Health Organisation. ${ }^{1}$ However, the decision to favour outpatient rather than hospital treatment of tuberculosis in many such countries has been influenced by several factors not mentioned in Squire and Wilkinson's editorial ${ }^{2}$ that were only alluded to in the two accompanying papers. ${ }^{34}$

Programmes to control tuberculosis are often the responsibility of the divisions for public health, primary healthcare, or control of communicable diseases within the countries' health ministries. Hospitals, particularly at secondary or tertiary referral level (provincial, regional, and university hospitals), usually fall under another division, or even another ministry. Those working in the control programme often have neither the authority nor the status to promote national policy guidelines in these hospitals. This may result in misdiagnosis, idiosyncratic drug regimens, and inadequate documentation and reporting for patients managed by hospitals. In contrast, community centres, clinics, and dispen- 
saries which are directly supervised by - often comparatively junior-programme staff can assume better control and contribute to programme activities in many ways.

The situation in private practice is even more confused. Patients may select only part of the treatment regimen because of the expense involved and may default from treatment after a few weeks, once they start to feel better. Attempts to trace such patients who drop out are rarely undertaken. Cooperation with the control programmewhich can help with training, open access to sputum microscopy services, free supplies of drugs, and accompanying monitoring-is essential if there is to be a unified strategy on how to treat the disease.

The national programme incorporating "DOTS" (directly observed treatment, short course) needs to be flexible. In Indonesia, a nominated observer (usually a relative, but it could be a neighbour or influential fellow villager) is briefed carefully and entrusted to be responsible for seeing every home dose taken. This observer can be as effective as a worker based at a health centre. Many patients have their disease diagnosed and documented, receive advice and encouragement, and are started on treatment at a health centre, with their nominated observer in attendance. These patients do not have to go to the district or provincial hospital. We are beginning to see satisfactory cure and completion rates from the rural area. The cities, however, are quite another problem.

Richard de Soldenhoff Regional medical officer Sulawesi (Support Programme from the

Netherlands Leprosy Relief Association to the

Government of Indonesia), Ujung Pandang. Indonesia

1 World Health Organisation. Report on the tuberculosis epidemic 1997. Geneva: WHO, 1997.

Squire SB, Wilkinson D. Strengthening "DOTS" through community care for tuberculosis. BMJ 1997;315:1395-6. 29 November.

3 Volmink J, Garner P. Systematic review of randomised controlled trials of strategies to promote adherence to tuberculosis treatment. BMJ 1997;315:1403-6. (29 November.)

4 Floyd K, Wilkinson D, Gilks C. Comparison of cost effectiveness of directly observed treatment (DOT) and conventionally delivered treatment for tuberculosis: experience from rural South Africa. BMJ 1997:315:140711. (29 November)

\section{Cognitive dysfunction after concussion}

\section{Authors did not to comment on the single truly significant result}

EDITOR-Teasdale and Engberg examined the duration of cognitive dysfunction after concussive head injury in young men. ${ }^{1}$ We are concerned about their interpretation of some of the data presented. The observation that cognitive function was impaired up to one week after head injury was based on examination of only eight subjects, four of whom showed impaired performance. The authors placed considerable weight on this result even though the relative risk of cognitive impairment in the subjects with head injury was not significant by conventional criteria. It was additionally perplexing, given this non-significant result, that the $95 \%$ confidence interval did not pass through unity. Perhaps most surprising of all was that the authors failed to comment on the one truly significant result in that section of the paper-that impaired cognitive performance was shown in those subjects tested more than 200 days after the head injury.

The other main finding, that the risk of concussion was greater in subjects with premorbid cognitive dysfunction, is readily understandable. It is disconcerting, however, that a similar degree of cognitive dysfunction was not apparent in subjects tested after head injury. The authors suggested that this may have been due to differences in the mean age of men tested before and after head injury (20.6 years and 18.0 years, respectively). There was indeed a greater frequency of dysfunctional scores in men injured at age $\leqslant 18$ than in those injured at age $\geqslant 19$. These data, however, were derived from the combined test results of men examined both before and after head injury. The authors' argument would be strengthened if a similar age difference were to be shown individually in both groups.

Mark W J Strachan Clinical research fellow Brian M Frier Consultant physician Department of Diabetes, Royal Infirmary of Edinburgh, Edinburgh EH3 9YW

Ian J Deary Professor of differential psychology Department of Psychology, University of Edinburgh, Edinburgh EH8 9JZ

1 Teasdale TW, Engberg A. Duration of cognitive dysfunction after concussion, and cognitive dysfunction as a risk factor: a population study of young men. BMJ 1997:315:569-72. (6 September)

\section{Authors' reply}

EDITOR-Our finding of an increased rate of cognitive dysfunction among subjects tested within one week of sustaining concussion was unsurprising given the numerous studies pointing to the same conclusion. ${ }^{1}$ The marginal lack of significance of the binomial test $(\mathrm{P}=0.06)$ is due to a lack of statistical power when only eight subjects are studied. That the lower limit of the $95 \%$ confidence interval for the risk ratio should nevertheless lie above unity (1.23) is certainly anomalous, but such discrepancies can arise given the different calculations involved.

Interpretation of significant cognitive dysfunction over 200 days after concussion needed to be deferred until the results for those injured after being tested were examined. It then seemed that there was an increased rate of cognitive dysfunction among subjects whether they were tested before or after sustaining concussion. This pointed to cognitive dysfunction being a risk factor for concussion. That the risk factor

Number (percentage) of men who were injured before or after test of cognitive function, by age at injury

\begin{tabular}{lccccccc}
\multirow{2}{*}{$\begin{array}{l}\text { Age at injury } \\
\text { (years) }\end{array}$} & \multicolumn{3}{c}{ Injury before test } & & \multicolumn{3}{c}{ Injury after test } \\
\cline { 2 - 3 } \cline { 7 - 8 } \cline { 7 - 8 } & Dysfunctional & Normal & Total & & Dysfunctional & Normal & Total \\
\hline$\leqslant 18$ & $150(24.8)$ & $456(75.2)$ & 606 & & $4(9.8)$ & $37(90.2)$ & 41 \\
\hline$\geqslant 19$ & $21(22.3)$ & $73(77.7)$ & 94 & & $154(32.2)$ & $325(67.8)$ & 479 \\
\hline Total & 171 & 529 & 700 & & 158 & 362 & 520 \\
\hline
\end{tabular}

had manifested itself more strongly in those subjects who were injured after being tested could have been due to their being relatively older at injury than those subjects injured before being tested (four fifths of whom were injured more than six months before testing). We found a lower rate of cognitive dysfunction among those injured at age $\leqslant 18$ than those injured at age $\geqslant 19$. Strachan et al suggest that this argument would be strengthened if both groups were subdivided according to whether they sustained concussion before or after being tested. The table shows the relevant data.

The table provides only partial support for our argument in that the age effect appears only among those injured after testing. There is, however, substantial confounding between age at injury and whether testing took place before or after the injury. Furthermore, dichotomising age involves a reduction of information. In a stepwise logistic regression we found age at injury to be significantly related to the test score (dysfunctional/normal) $\quad(\mathrm{P}=0.017), \quad$ and thereafter there was no significant contribution of injury before or after testing $(\mathrm{P}=0.45)$. In default of alternative hypotheses, we therefore continue to believe that the poorer performance in cognitive tests of those young men who were tested before they sustained concussion may well be explained by factors related to their relatively greater age at injury.

Thomas W Teasdale Associate professor

Psychological Laboratory, University of Copenhagen, 2300 Copenhagen S, Denmark

Aase Engberg Senior resident

Department of Neurology, Odense University

Hospital, 5000 Odense C, Denmark

1 Bohnen N, Jolles J. Neurobehavioral aspects of postconcussive symptoms after mild head injury. J Nerv Ment Dis 1992;180:683-92.

\section{Determining prognosis after acute myocardial infarction in the thrombolytic era}

\section{Rescue angioplasty after failed thrombolysis may put patients at risk}

Editor-Beller brings to readers' attention the fact that routine invasive procedures after acute myocardial infarction offer no significant benefit over that offered by the routine practice of risk stratification with non-invasive methods. ${ }^{1}$ We are concerned, however, with the blanket statement that high risk patients should have early angioplasty or rescue angioplasty after failed thrombolysis. This technique should be used with caution.

A meta-analysis by Ellis et al indicated a mortality of $10.6 \%$ after the procedure, either 
from the disease process or as a direct complication of the procedure. ${ }^{2}$ Furthermore, this procedure fails in $20 \%$ of cases and those failed cases have a mortality of $40 \%$. Vigorous clinical assessment is therefore necessary before a patient is classified as being at high risk. Inadequate optimisation of supportive treatment often leads to signs such as hypotension and sinus tachycardia, which in turn predispose to further chest pain, interpreted as postinfarction angina even in the absence of electrocardiographic changes. Chest crepitations related to aging are often confused with those associated with pulmonary oedema. One prime example is inferior myocardial infarction with right ventricular extension. This is due to an occlusion of a dominant right coronary artery, which carries a relatively good prognosis. Suboptimal fluid replacement and the indiscriminate use of inotropic agents without prior careful assessment of left ventricular function with echocardiography and guidance by SwanGanz catheterisation lead to patients being classified as at high risk without having prior or incidental left coronary artery disease.

The fact that rescue angioplasty for right coronary artery occlusion is associated with excessive complications ${ }^{3}$ should lead doctors to question whether this form of intervention is putting a patient's life at risk, turning a relatively benign course into a fatal one.

Pitt Lim Clinical lecturer

Paul Shiels Research fellow

Department of Clinical Pharmacology and Cardiology, Ninewells Hospital and Medical School, Dundee DD1 9SY

1 Beller GA. Determining prognosis after acute myocardial infarction in the thrombolytic era. BMJ 1997;315:761-2. (27 September.)

2 Ellis SG, Van de Werf F, Ribeiro-daSilva E, Topol EJ Present status of rescue coronary angioplasty: current polarisation of opinion and randomised trials. JACC 1992;19:681-6.

3 De Franco AC, Ellis SG. Rescue angioplasty. In: Sigwart U, Bertrand M, Serruy PW, eds. Handbook of cardiovascular interBertrand M, Serruy PW, eds. Handbook of cardiovascular
vention. Edinburgh: Churchill Livingstone, 1996:431-48.

\section{Author's reply}

EDITOR-Lim and Shiels make a valid point regarding the increased risk of rescue angioplasty after presumed failed thrombolysis, but I never addressed the issue of early angioplasty in my editorial. The thrust of my discussion regarding risk stratification related to the identification of clinical variables and variables determined with non-invasive tests that could be used to select those patients after infarction who are most likely to benefit from coronary angiography and coronary revascularisation.

With respect to clinical variables, I mentioned that the combination of rales in over a third of the lung field, hypotension, and sinus tachycardia on admission was an important observation that indicated a high risk status, since these haemodynamic alterations reflect a large area of myocardium at jeopardy with ischaemia or necrosis, or both; they can also point to underlying multivessel disease or a large infarct, or both. I agree that each one of these haemodynamic changes in isolation is not highly specific for a high risk designation. Certainly, crackles at the lung bases alone without evidence of other signs of left ventricular pump failure can indicate atelectasis or pulmonary disease. Hypotension in isolation, without sinus tachycardia and pulmonary rales, can be due to volume depletion or right ventricular infarction and not be secondary to extensive left ventricular dysfunction.

The main message of my editorial was that a routine invasive strategy for risk assessment before discharge is not superior to a watchful waiting, non-invasive strategy in which patients undergo angiography for high risk clinical findings or for spontaneous or inducible ischaemia within or remote from the infarct zone. Recent data reported from the VA non-Q wave infarction strategies in-hospital trial, in which 920 patients with non- $Q$ wave infarction were randomised to an initial invasive strategy or an initial conservative strategy, support this approach. ${ }^{1}$ At one year after discharge there was no difference in cardiac death or recurrent infarction between the two groups. Also, new data from Yusuf et al showed no difference in outcome for patients with infarction admitted to hospitals with cardiac catheterisation facilities (catheterisation rate $66 \%$ ) compared with those admitted to hospitals with no catheterisation facilities on site (catheterisation rate $34 \%)^{2}{ }^{2}$

George A Beller Chief

Cardiovascular Division, Department of Internal

Medicine, University of Virginia Health Sciences

Center, Charlottesville, VA 22908, USA

\section{Boden WE, O'Rourke RA, Dai H, Crawford MH, Blaustein AS, Deedwania PC, et al. Improved clinical outcomes in non-Q-wave infarction patients randomized to a conserva- tive "ischemia-guided" strategy compared to an invasive interventional strategy: results of the multicenter VA non- Q-wave infarction strategies in-hospital (VANOWISH) trial [abstract]. Circulation 1997;96(suppl I):207. \\ 2 Yusuf S, Flather MD, Pogue JM, Hunt D, Varigos J, Piegas LS, et al. Factors affecting the use of invasive facilities in pstients wh unte a patient with unt}

\section{Number of unexplained symptoms and diseases is decreasing}

Editor-In his editorial Mayou explains that the management of patients with medically unexplained physical symptoms is too often inappropriate, even though effective interventions are available. ${ }^{1} \mathrm{He}$ essentially attributes this to the persistence of the idea of "mind-body dualism" in the medical profession, which neglects important interactions between physiological, psychological, and social factors.

I agree with what he says about this socially and economically important subject, but I would emphasise another factor: our scientific ignorance and frequent arrogance. Too easily and too frequently we attribute to mental illness symptoms that turn out to be those of well defined organic diseases (which does not exclude the role of superimposed social or psychological factors). Mayou says "there is scant provision ... for the patient with somatic complaints who has neither physical disease nor severe mental illness."
This sentence reminds us that these patients tend to be forgotten, but "recognised" or "known" should probably have preceded the term "physical disease."

Patients with muscular symptoms are a good example of this. Many, classified years ago as mentally ill, later turned out to have well defined disease. A typical example is patients with McArdle's disease, who suffer from chronic muscle fatigue with exercise. Many-at least, the older ones-were initially classified as having purely psychological or psychiatric disease; they were consequently regarded as being lazy and dealt with as such, typically when they were conscripted into the army. Even worse, they were usually forced to exercise, which has since been shown to be potentially dangerous since it can lead to muscle damage and renal failure. They are now known to have a genetically determined lack of a muscle enzyme essential for glycogen breakdown and use for energy production (muscle phosphorylase deficiency).

These errors of classification have moral, psychological, and economic implications for patients, their families, and society. Some doctors still seem to be unaware of their own ignorance. We should be modest and cautious, perhaps stating that our conclusions are "to the best of our knowledge" and may not be correct. Even though the list of unexplained diseases and symptoms is slowly decreasing through scientific progress, it is unlikely ever to disappear totally.

Philippe Jehenson Medical researcher Service Hospitalier Frédéric Joliot, Commisariat à l'Energie Atomique, 91406 Orsay, France

1 Mayou R. Treating medically unexplained physical symptoms. BMJ 1997;315:561-2. (6 September.)

\section{The caring doctor is an oxymoron}

\section{General practice will develop best if "caring" is replaced by professionalism}

EditoR-Mackenzie's hypothesis that the term "the caring doctor" is an oxymoron struck a chord with many doctors I speak to. ${ }^{1}$ I have long thought that general practice will develop best if we replace the sham of caring with better professionalism. This does not stop us practising good medicine in a compassionate and considerate manner. We spend a lot of time teaching consulting skills to registrars. Good consulting is not the same as "niceness," and the term "the caring professions" is patronising and arrogant.

There is still a place for the registered list of patients, but in a computerised world it is a tool for targeting and delivering good medicine-for example, in secondary prevention. The modern world is demanding of us. If general practice is to remain vibrant and attract high quality recruits we have to develop practice beyond the personal attributes of individual doctors. We need to think imaginatively, to continue the drive for better organisation, to use information technology to the full, to recognise the strengths of other members of the team, to delegate 
and give up some of our traditional perceived duties to those who often do them better. Surely routine visiting is a thing of the past.

Practitioners as team leaders need to have the time and energy to step back and look critically at what the practice does as a whole and not to be afraid to initiate change. Too much of what we do still depends on tradition rather than planning. This opens the doors to external influences, as we have seen in the past few years to our disadvantage.

Clinical audit should no longer be a threat to most of us, and perhaps we need to open the debate about clinical outcomes in practice. This debate should include the limitations that patients should expect of our services, and their responsibilities towards their own health. It should be aimed at reducing the dependency on doctors that seems to be ingrained in some quarters-for example, for numerous prescriptions for minor illness.

I suspect that patients in general would support attempts to improve services at the expense of personal doctoring, which is probably more important to some doctors than to most patients. Inevitably this may touch on the question of standards, but if the debate is open and the standards explicit then most of us have nothing to fear.

Alastair D Short General practitioner

Anniesland Medical Practice, Glasgow G13 1LU

1. Mackenzie GM. The caring doctor is an oxymoron. $B M$ 1997;315:687-8. (13 September.)

\section{Frequent callers to cooperatives provoke} same feelings there

EDITOR-I strongly disagree with Mackenzie's contention that patients receive better care from doctors who work in a cooperative than from their own general practitioner. ${ }^{1}$ In my experience, doctors who work in a cooperative provide safety-first, firefighting medicine to deal with acute problems. The decision rests between admitting the patient to hospital or managing him or her at home until the next day. The lack of notes and an accurate, reliable medical history is certainly not a bonus and can be a major hindrance. Most cooperatives rapidly get to know their frequent callers, who provoke the same feelings out of hours as they do in their own practice.

Familiarity can breed contempt, but being aware of this risk can prevent missed diagnoses. Familiarity can also provide huge benefits for somatisers in rescuing them from repeated investigations by doctors unfamiliar with their history. If all patients were seen by doctors working in cooperatives, fat files would be even fatter and surgeries would resemble hospital outpatient clinics, where patients see a different senior house officer at every visit.

To me the oxymoron is "depersonalised general practice." Let's improve our consultation skills and not lose the benefits of long term continuity of care.

Carol Blow General practitioner

17 Lower Road, Fetcham, Surrey KT22 9EI

Mackenzie G. The caring doctor is an oxymoron. $B M$ 1997;315:687-8. (13 September.)

\section{GPs will soon become extinct}

EDIToR-Mackenzie's personal view was undoubtedly intended to be provocative. ${ }^{1}$ I was provoked, not only to consult my dictionary on that curious word "oxymoron" but also to challenge Mackenzie's profoundly negative view of personal care in general practice.

There is a growing danger that the best feature of Britain's NHS (the family doctor who visits patients in their homes) will soon become extinct, driven to the wall by the primary care physician with his or her burgeoning team and an efficient computer system. What is wrong with being both clinically and administratively efficient and preserving that special bond between ill people and the doctor who knows them best?

Bring back the individual commitment, the romance, and the poetry into general practice.

John Rawlinson General practitioner

The Medical Centre, Hunters Way, Kimbolton, Huntingdon, Cambridgeshire PE18 0JF

1 Mackenzie GM. The caring doctor is an oxymoron. BMJ 1997;315:687-8. (13 September.)

Out of hours emergencies and continuing problems need different approaches

EDITOR-Mackenzie's argument in his article entitled "The caring doctor is an oxymoron" is based on the central assumption that, with improving records and information technology, most doctors should have enough information to negate the usefulness of patients seeing doctors who think that they know the patients well. ${ }^{1}$ I disagree.

It is my experience that in general practice, as in the whole of medicine, the state of medical records and information technology is still far removed from such an ideal. Consultation records are often partial, illegible, or completely absent. Current and past problem summaries are frequently incomplete, and attempting to obtain the information from the patient is time consuming and often fruitless. Therefore continuity of care in general practice continues to be valuable because the familiar doctor's memory can compensate for many of these deficiencies.

Mackenzie does not mention the time that new doctors take to read even the most perfect of medical records to update themselves fully on a patient's progress to date. This eats into valuable consultation time. If the patient sees a familiar doctor then this time is saved.

Finally, I take issue with Mackenzie's argument about the superiority of care provided by doctors working in cooperatives over that provided by the patient's own general practitioner. Even if this were true in general (which I doubt) it is only partially relevant as it relates to out of hours emergency consultations. By their nature, out of hours emergencies are amenable to care by any general practitioner with only an outline of the patient's medical history. The more complex continuing problems, with their mixture of physical, psychological, and social aspects, which are the meat of general practice during working hours, require a different approach.
I believe that continuity is essential for efficient care-quite apart from any sentimental attachment to the idea of the "cradle to grave" doctor.

H Tooby General practitioner

The Ridge Medical Practice, 3 Paternoster Lane, Great Horton, Bradford BD7 3EE

1 Mackenzie GM. The caring doctor is an oxymoron. BMJ 1997:315:687-8. (13 September)

\section{GPs could refer patients to clinica hypnotherapists}

EDITOR-Mackenzie believes that the term "a caring doctor" is an oxymoron, maintaining that, at least in general practice, "overpersonalising care can result in poor delivery of appropriate medicine." I believe that by removing the personal touch he is missing out on a valuable, but time consuming, therapeutic tool. He dislikes the "caring doctor" approach because of its effect on general practitioners' morale, saying that what wears general practitioners down is the "constant assault from the same people, which dulls the intellect and forces general practitioners to operate in a completely different way from how their training taught them."

Of course, being nice takes time-a precious commodity. Being nice, however, is a valuable therapeutic tool in itself whose value is often overlooked. Doctors who believe that their abilities should be assessed solely on their performance as clinicians are not necessarily providing all the help that some of their patients need.

Mackenzie's underlying implication is that good clinicians do not expect to see their patients either for very long or for many repeat visits. So what does that make doctors who cannot seem to get rid of some patients? Are they bad clinicians? Of course not. The patients are benefiting in some way from the visit itself, otherwise they wouldn't come. But the benefit does not come out of a bottle, cannot easily be quantified, and does not show up in an audit in a positive way.

Once a general practitioner has tried all the medical options, perhaps another form of help is more appropriate for those patients who will not go away. Patients now recognise that doctors do not have all the answers, and it has become acceptable for doctors to receive help themselves. If doctors feel uncomfortable being nice and spending extra time with particular patients then they can now refer them to another source of help, a clinical hypnotherapist: one who has the time to be nice to patients and has been professionally trained to encourage them to take responsibility for themselves and deal with their own problems. This will certainly unclog the surgery systems, freeing the doctors to see those patients they can help most effectively, reducing their stress, improving their morale, and, dare I say it, even helping the patient too.

Tony Pitcairn Organising secretary British Society of Clinical Hypnotherapists 7 Middleton Avenue, Ilkley, West Yorkshire LS29 0AD

1 Mackenzie GM. The caring doctor is an oxymoron. BMJ 1997;315:687-8. (13 September) 